\title{
Apolipoprotein E polymorphism is associated with age of onset in schizophrenia
}

Received: 7 January 2004 / Accepted: 26 March 2004/Published online: 18 June 2004

(C) The Japan Society of Human Genetics and Springer-Verlag 2004

\begin{abstract}
The aims of the study were to investigate the relationship between Apolipoprotein E (APOE) polymorphism, risk of schizophrenia, treatment response to conventional anti-psychotics, and age of onset in schizophrenia. The sample comprised 94 Finnish patients with a DSM-IV diagnosis of schizophrenia. Forty-three of the patients were good responders to conventional anti-psychotics and 51 were classified as non-responders. The control group consisted of 98 healthy blood donors. The $A P O E$ allele frequencies $(\varepsilon 2$, $\varepsilon 3$, and $\varepsilon 4$ ) were $4.8,72.3$, and $22.9 \%$ in patients and 7.1 , 75.0 , and 17.9 in controls. None of the differences between groups were statistically significant. No association between treatment response and $A P O E$ genotype was found. Patients with $A P O E \& 4 / \varepsilon 4$ genotype had a markedly lower age of onset compared with rest of the
\end{abstract}

O. Kampman $(\bowtie) \cdot S$. Anttila $\cdot$ A. Illi $\cdot$ K. M. Mattila

R. Rontu · E. Leinonen · T. Lehtimäki

Medical School, University of Tampere,

33014 Tampere, Finland

E-mail: olli.kampman@uta.fi

Tel.: + 358-40-7023232

Fax: + 358-3-2156164

O. Kampman

Department of Psychiatry,

Seinäjoki Hospital District,

62200 Seinäjoki, Finland

S. Anttila $\cdot$ K. M. Mattila $\cdot$ R. Rontu $\cdot$ T. Lehtimäki

Laboratory of Atherosclerosis Genetics,

Department of Clinical Chemistry,

Centre for Laboratory Medicine,

Tampere University Hospital, Teiskontie 35,

PL 2000, 33521 Tampere, Finland

A. Illi

Department of Psychiatry,

Kanta-Häme Central Hospital,

13530 Hameenlinna, Finland

E. Leinonen

Department of Psychiatry,

Tampere University Hospital,

33380 Pitkaniemi, Finland sample $(p=0.0015)$, which remained significant when controlling for gender $(p=0.02)$. There was an increasing linear trend between the number of $\varepsilon 3$ alleles $(0,1$, or 2 ) and age of onset in schizophrenia $(p=0.08)$. An inverse trend was found between the number of $\varepsilon 4$ alleles and age of onset $(p=0.07)$. No relationship between $A P O E$ polymorphism and risk for schizophrenia was found. $A P O E \& 4 / \varepsilon 4$ genotype may be associated with early onset schizophrenia. $A P O E \& 3$ allele may function protectively in later onset in this disease.

Keywords Schizophrenia - Genetics $\cdot$ Pharmacogenetics $\cdot$ Apolipoprotein $E \cdot$ Anti-psychotic agents

\section{Introduction}

Apolipoprotein $E$ (apoE) is a major lipid-binding protein in the brain. It is expressed in humans as three common isoforms coded by three different alleles, $A P O E \varepsilon 2, \varepsilon 3$, and $\varepsilon 4$, resulting in six genotypes $(\varepsilon 2 / 2, \varepsilon 2 / 3, \varepsilon 2 / 4, \varepsilon 3 / 3$, $\varepsilon 3 / 4$, and $\varepsilon 4 / 4$ ) (Siest et al. 2000). The $A P O E$ isoforms are characterized by the presence of amino acid Cys ( $A P O E 2$ and $A P O E 3)$ or $\operatorname{Arg}(A P O E 4)$ at position 112 of the mature $A P O E$ polypeptide chain and $\operatorname{Arg}(A P O E$ 3 and $A P O E$ 4) or Cys (APOE 2) at position 158 (Weisgraber et al. 1981). These amino acid changes result from two single nucleotide polymorphisms of the $A P O E$ gene at nucleotide positions 334 and 472 . The combinations 334T/472T (112 Cys/158 Cys), 334T/472C (112 Cys/158 Arg), and 334C/472C (112 Arg/158 Arg) constitute the known isoform-specific $A P O E$ alleles, $\varepsilon 2, \varepsilon 3$, and $\varepsilon 4$, respectively (Siest et al. 1995). To our knowledge, the combination 334C/472T (112 Arg/158 Cys) has never been observed.

ApoE is synthesized and secreted in the liver, brain, and skin tissues, and its primary metabolic role is to transport and deliver lipids from one tissue or cell to another (Mahley and Rall 2000). The APOE \&4 allele is associated with the risk of hypercholesterolemia, coro- 
nary artery disease, and several neurological disorders. $A P O E$ is a major susceptibility gene associated with lateonset Alzheimer's disease and with clinical outcome in patients with stroke (Mahley and Rall 2000).

More than 20 papers dealing with $A P O E$ polymorphism and schizophrenia have been published since 1995 (Dean et al. 2003; Schurhoff et al. 2003; Sutcliffe and Thomas 2002). The majority of these studies have shown no association between $A P O E$ polymorphism and schizophrenia. The frequency of $\varepsilon 4$ allele was associated with schizophrenia in a study by Harrington et al. (1995), and the finding was replicated in a large Chinese sample by Liu et al. (2003). According to a recent metaanalysis (Schurhoff et al. 2003), the frequency of $\varepsilon 3$ has been shown to be increased in patients with schizophrenia in an Asian population but not in Caucasians.

Early age of onset in schizophrenia has been associated with an excess of $\varepsilon 4$ allele in two different samples (Arnold et al. 1997; Martorell et al. 2001), but in the study by Igata-Yi et al., the frequency of $\varepsilon 4$ was lower in the early onset group (Igata-Yi et al. 1997). Saiz et al. reported no association between the frequency of $\varepsilon 4$ and age of onset (Saiz et al. 2002). The frequency of $\varepsilon 2$ was found to be decreased in early-onset schizophrenia in a study by Kimura et al. (1997). Durany et al. (2000) found no significant difference in the frequency of $\varepsilon 4$ allele in Spanish patients with early-age onset compared with late-onset patients. Pickar et al. reported drug-free patients with $\varepsilon 4$ allele to have lower levels of psychotic symptoms than patients without $\varepsilon 4$ allele (Pickar et al. 1997).

Poor response to typical neuroleptics in schizophrenia was also studied with Spanish patients, but no association with $A P O E$ genotype or allele distribution was found (Durany et al. 2000). The treatment response to clozapine with nonresponders to typical neuroleptics has shown no association with the presence of $\varepsilon 4$ (Hong et al. 2000). In affective disorders, a higher frequency of $\varepsilon 4$ allele has been associated with a rapid onset of mirtazapine action, slow response to paroxetine (Murphy et al. 2003), and with a better response to electroconvulsive therapy (Fisman et al. 2001). In a recent study, postmortem analysis of patients with schizophrenia revealed higher levels of apoE in the Brodmann's area. In rats, administering haloperidol resulted in decreased apoE levels in analogous areas (Dean et al. 2003).

The aims of the present study were to examine the frequencies of $A P O E$ alleles in a Finnish population with schizophrenia. On the basis of previous results, we hypothesized that $\varepsilon 4$ allele may be associated with better response to typical neuroleptics and with earlier-onset schizophrenia.

\section{Methods}

\section{Subjects}

We studied 94 unrelated Finnish patients with schizophrenia (Table 1). An experienced psychiatrist interviewed all the patients and checked the diagnoses according to the DSM-IV criteria by evaluating hospital records.

Patients in the responder group (group 1, $n=43$ ) had experienced a sufficient and long-lasting response to treatment with conventional neuroleptics. Assessment of response was based on information in hospital and mental health care records and a personal interview with each patient. Before initiation of neuroleptic treatment, the severity of schizophrenic symptoms had to be $\geq 4$ according to the clinical global impression (CGI) scale. The patients in the nonresponder group (group 2, $n=51$ ) were those with clozapine medication who had failed to respond on at least two different occasions to treatment with two different conventional antipsychotics during hospitalization. In each treatment period, the lowest accepted daily dose was $400 \mathrm{mg}$ chlorpromazine equivalent for a minimum of 4 weeks. Prior to the initiation of clozapine treatment, the severity of schizophrenic symptoms had to be $\geq 4$ on the CGI scale, and at least one of the following symptoms had to be present: conceptual disorganization, suspiciousness, hallucinatory behavior, or unusual thought content. A greater proportion of men $(62.2 \%)$ than women $(45.8 \%)$ was selected for group 2, but the difference was not statistically significant $\left(p=0.17, \chi^{2}\right)$. Age of onset was determined as the patient's age during the first hospitalization at which the diagnosis of schizophrenia was used. This data was obtained from the hospital discharge register. In the Nordic countries, the proportion of identified cases with schizophrenia in an inpatient register is high, despite different ages of onset (Dalman et al. 2002).

The controls were 98 age- and gender-matched blood donors. In Finland, the subjects complete a written health statement, including neurological and mental health, at every blood donation session. The study was carried out in compliance with the code of ethics of the World Medical Association (Declaration of Helsinki) and the standards established by the local medical ethics committee. The participants gave written informed consent.
Table 1 Patient characteristics

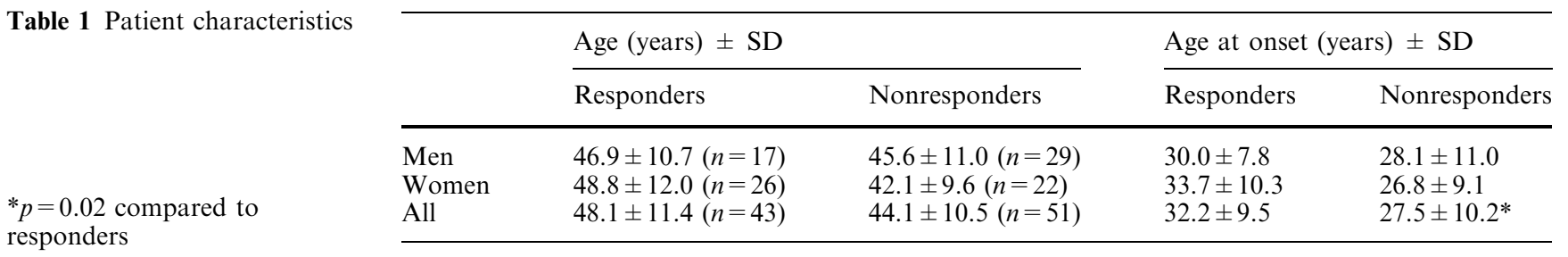

$* p=0.02$ compared to responders 


\section{$A P O E$ genotyping}

Genomic DNA was extracted from peripheral blood leukocytes using a commercially available kit (Qiagen, Inc., Hilden, Germany). For the APOE 112 genotyping, we used fluorogenic allele-specific TaqMan probes and primers as previously described (Koch et al. 2002). $A P O E 158$ genotypes were determined using allele-specific fluorogenic probes with conjugated minor groove binder group (Livak 1999). The nucleotide sequences of the APOE 158 primers and probes used in the PCR were deduced from published sequences deposited in the GenBank database and were chosen and synthesized in conjunction with Applied Biosystems (Foster City, CA, USA) using the Assay-by-Design tool. DNA samples were genotyped by employing the $5^{\prime}$ nuclease assay for allelic discrimination using the ABI Prism 7000 Sequence Detection System (Applied Biosystems). PCR reaction containing genomic DNA, $1 \times$ Universal PCR Master Mix, $900 \mathrm{nM}$ of each primer, and $200 \mathrm{nM}$ of each probe was performed in 96-well plates using the standard protocol in a total volume of $25 \mu \mathrm{l}$. Water controls and known control samples previously typed by RFLP-PCR analysis were run in parallel with unknown DNA samples. After cycling, end-point fluorescence was measured, and genotype calling was carried out by the allelic discrimination analysis module.

\section{Statistical methods}

Pearson $\chi^{2}$-test was used to compare allele frequencies between different study groups. The association of $\varepsilon 4$ allele and age of onset was analyzed with the KaplanMeier test and with analysis of covariance controlling for gender. In analyses regarding $\varepsilon 3$ and $\varepsilon 4$ alleles and age of onset non-parametric tests (Mann-Whitney $U$ test and median test) were used. The limit of statistical significance was set at 0.05 . Data analysis was carried

Table 2 Apolipoprotein $E$ ( $A P O E$ ) allele frequencies and differences between groups

\begin{tabular}{lcccl}
\hline & \multicolumn{1}{c}{$\varepsilon 2$} & \multicolumn{1}{c}{$\varepsilon 3$} & \multicolumn{1}{l}{ T4 } & \multicolumn{1}{l}{ Total } \\
\hline Patients & $9(4.8 \%)$ & $136(72.3 \%)$ & $43(22.9 \%)$ & $188(100 \%)$ \\
Controls & $14(7.1 \%)$ & $147(75.0 \%)$ & $35(17.9 \%)$ & $196(100 \%)$ \\
$\chi^{2}$ & 1.01 & 0.46 & 1.94 & \\
test and & $(p=0.32)$ & $(p=0.80)$ & $(p=0.38)$ & \\
significance & & & & \\
\hline
\end{tabular}

out using SPSS/Win software (Version 11.5, SPSS, Inc., Chicago, IL).

\section{Results}

The distributions of $A P O E$ alleles as well as genotypes in both control and patient groups and ages of onset in schizophrenia with each genotype are presented in $\mathrm{Ta}-$ bles 2, 3. APOE polymorphism was not associated with schizophrenia. None of the $A P O E$ alleles was associated with treatment response to typical neuroleptics $(\varepsilon 2+$ versus $\varepsilon 2-, p=0.94 ; \varepsilon 3+$ versus $\varepsilon 3-, p=0.32 ; \varepsilon 4+$ versus $\varepsilon 4-, p=0.13$ )

$A P O E \varepsilon 4 / \varepsilon 4$ genotype was associated with age of onset in schizophrenia ( $p=0.0015, \log$ rank test). When controlling for gender, this association remained significant ( $p=0.02$, ANCOVA). There was a negative trend between the number of $\varepsilon 4$ alleles and age of onset $(p=0,07$, median test), which is shown in Fig. 1 .

$A P O E$ \&3 allele also showed a tendency towards an association with age of onset in schizophrenia. With this allele, the $\varepsilon 3$ - group $(n=8)$ had lower age of onset than the $\varepsilon 3+$ group $(n=86) \quad(p=0.04$, Mann-Whitney $U$ test). In a comparison between age of onset and the number of $\varepsilon 3$ alleles, a similar trend was found, and this is shown in Fig. 2 ( $p=0.08$, median test).

\section{Discussion}

This is the first study dealing with $A P O E$ polymorphism in a Finnish population with schizophrenia. Our results are in accordance with the majority of previous studies in finding no relationship between $A P O E$ polymorphism and incidence of schizophrenia. According to the metaanalysis by Schurhoff et al. (2003), the APOE polymorphism is not associated with schizophrenia in Caucasians, but in Asian populations an excess of $\varepsilon 3$ was found in patients with schizophrenia. The frequency of $\varepsilon 4$ allele was somewhat lower in our sample compared to earlier findings in northern European populations (Gerdes 2003; Mahley and Rall 2000), although this difference remains within the normal variation between study samples. For example, Jonsson et al. (1996) reported the $\varepsilon 4$ frequency as $18.4 \%$ in Swedish patients with schizophrenia.

The study by Hong et al. has so far reported an association between clinical response to clozapine in schizophrenia and $A P O E \& 4$ allele (Hong et al. 2000).
Table 3 Apolipoprotein $E$ $(A P O E)$ genotypes in controls and patients and age of onset with schizophrenia

\begin{tabular}{llcccccc}
\hline & $\varepsilon 2 / 2$ & $\varepsilon 2 / 3$ & $\varepsilon 2 / 4$ & $\varepsilon 3 / 3$ & $\varepsilon 3 / 4$ & $\varepsilon 4 / 4$ & Total \\
\hline Controls & 0 & 10 & 4 & 55 & 27 & 2 & 98 \\
Patients & 0 & 6 & 3 & 50 & 30 & 5 & 94 \\
Age of onset (years) & & 28.3 & 30.0 & 30.2 & 30.2 & 20.6 & 29.6 \\
Mean & & 8.8 & 16.5 & 10.4 & 9.9 & 3.1 & 10.1 \\
SD & & &
\end{tabular}




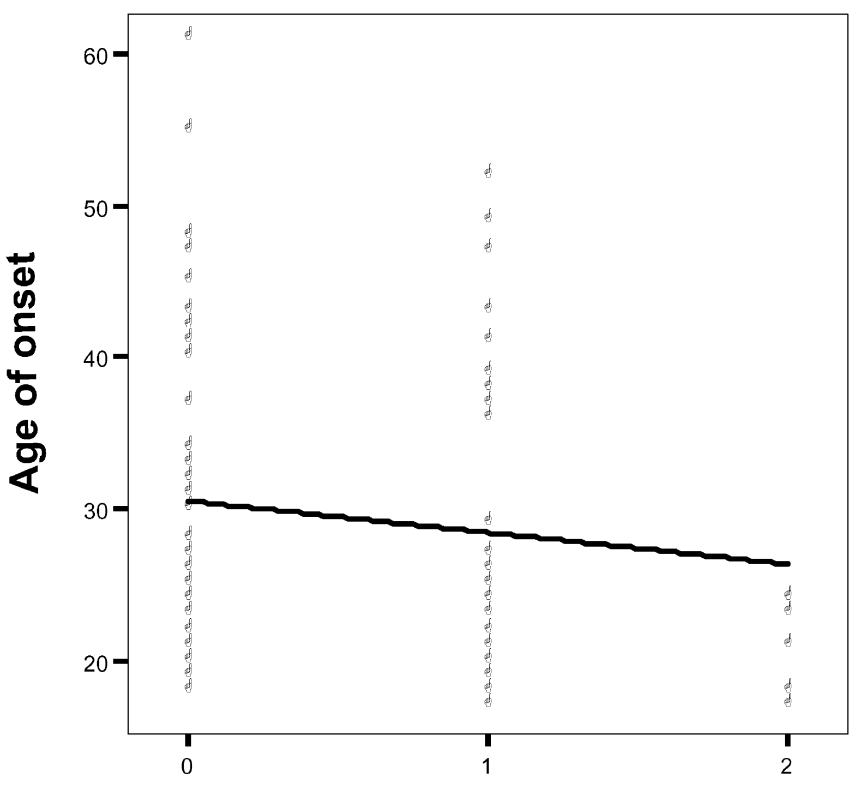

Number of $\varepsilon 4$ alleles

Fig. 1 A trend between age of onset and the number of $\varepsilon 4$ alleles $(0,1$, or 2 alleles) is shown in three groups of patients with schizophrenia by a regression line $(p=0.07$, median test)

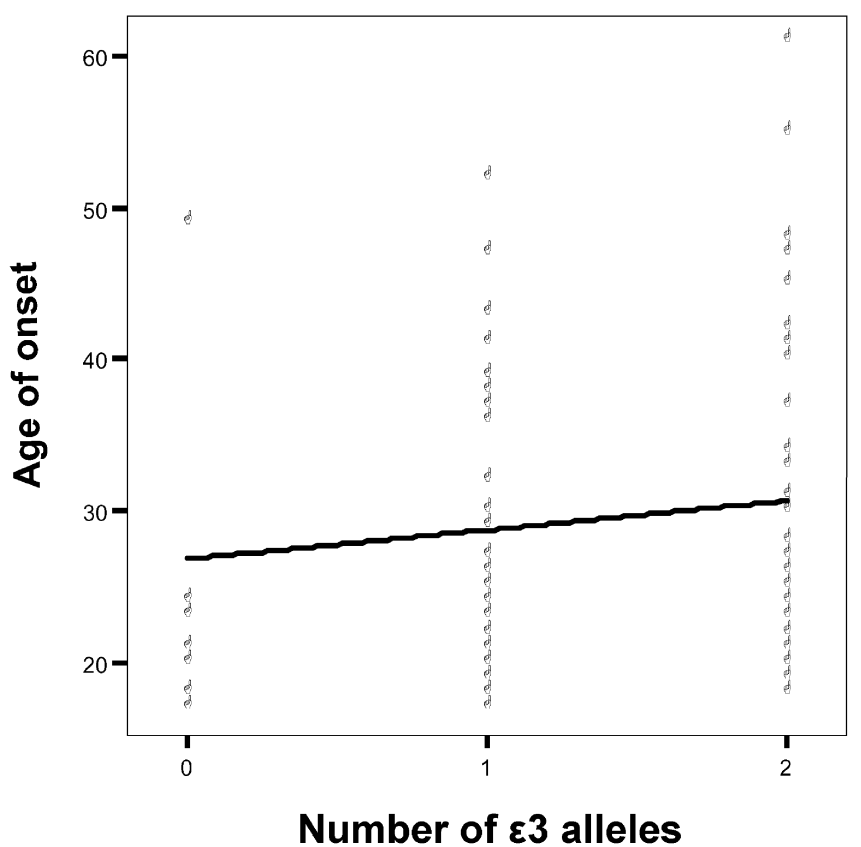

Fig. 2 A trend between age of onset and the number of $\varepsilon 3$ alleles $(0,1$, or 2 alleles) is shown in three groups of patients with schizophrenia by a regression line $(p=0.08$, median test)

Durany et al. found no relationship between $A P O E$ genotype and response to conventional antipsychotics (Durany et al. 2000). This finding was replicated in our sample. Unfortunately, the criteria for response have not been reported by Durany et al. making the comparison of the results difficult. In the present study, the restricted sample size may have produced results with limited reliability, especially in the comparison between the schizophrenia subgroups.

The control population underwent no specific examination for psychiatric status. However, eligibility for blood donors in Finland requires a written statement regarding health status at every donation session, and in our opinion, the blood donors represent a part of the general population without chronic diseases or regular medications.

The age of onset with schizophrenia was determined according to information in the hospital discharge register, which has shown high validity with schizophrenia between different ages of onset (Dalman et al. 2002). Although most of the patients in Finland with first schizophrenic psychosis are hospitalized, it is possible that mild or atypical symptoms in some patients may have caused a delay before accurate diagnosis in clinical setting.

The patients with $\varepsilon 4 / \varepsilon 4$ genotype had a markedly earlier age of onset compared with the rest of our sample. The frequency of 83 allele also showed an increasing linear trend in association with the age of onset. An inverse trend was seen with $\varepsilon 4$ allele and age of onset. Due to skewed distribution in the group without 83 allele, statistical analyses were performed with nonparametric tests resulting in borderline levels of significance between groups, and therefore, these results should be interpreted cautiously. However, in the study by Arnold et al. (1997), a linear association between age of onset and $A P O E$ genotype was found, and $\varepsilon 3$ allele was regarded as a neutral factor regarding age of onset. Martorell et al. also reported an association between the presence of $\varepsilon 4$ allele and early age of onset in women (Martorell et al. 2001). Our findings suggest that $\varepsilon 3$ allele serves as a protective factor, and its absence could be associated with a higher risk for early-onset schizophrenia, whereas $\varepsilon 4$ allele is a risk factor for earlier onset. Arnold et al. (1997) also reported the $\varepsilon 2$ allele function as a protective factor with the onset of schizophrenia. However, the gene-dosage effect could not be studied in our sample due to lack of $\varepsilon 2 / \varepsilon 2$ among patients.

The possible mechanism between earlier onset in schizophrenia and $A P O E$ genotype involves an increase of apoE levels in the prefrontal cortex in patients with two $\varepsilon 4$ alleles, which has been found in subjects with Alzheimer's disease (Thomas et al. 2003). There is evidence that apoE levels are elevated in frontal cortical area in patients with schizophrenia (Dean et al. 2003). Nathan et al. have studied the capability of apoE3 and E4 isoforms to modulate neurite outgrowth in adult mouse cortical neurons. They discovered that treatment with apoE3 increased both neurite extension and combined length in a dose-dependent fashion, whereas the functions of apoE4 were the opposite, i.e., a decrease in both effects (Nathan et al. 2002). Hata et al. observed a trend toward decreased hippocampal volume and asymmetry in subjects with schizophrenia and $\varepsilon 4$ allele (Hata et al. 2002). 
In conclusion, $A P O E$ polymorphism is not associated with an elevated risk of schizophrenia or with treatment response with conventional antipsychotics. APOE $\varepsilon 4 / \varepsilon 4$ genotype and the absence of $\varepsilon 3$ allele may predispose to early onset in schizophrenia.

Acknowledgements This study was supported by grants from the Medical Research Fund of Tampere University Hospital. The authors wish to thank Drs. Markus Roivas, Vesa Lassila, and Tuula Ristilä for their help in recruiting the patients. The authors also extend their warmest thanks to laboratory nurse Marita Koli for her skillful technical assistance and psychiatric nurse Nina Kilkku, MNSc., for her assistance in recruiting patients.

\section{References}

Arnold SE, Joo E, Martinoli MG, Roy N, Trojanowski JQ, Gur RE, Cannon T, Price RA (1997) Apolipoprotein E genotype in schizophrenia: frequency, age of onset, and neuropathologic features. Neuroreport 8:1523-1526

Dalman C, Broms J, Cullberg J, Allebeck P (2002) Young cases of schizophrenia identified in a national inpatient register-are the diagnoses valid? Soc Psychiatry Psychiatr Epidemiol 37:527531

Dean B, Laws SM, Hone E, Taddei K, Scarr E, Thomas EA, Harper C, McClean C, Masters C, Lautenschlager N, Gandy SE, Martins RN (2003) Increased levels of apolipoprotein E in the frontal cortex of subjects with schizophrenia. Biol Psychiatry 54:616-622

Durany N, Riederer P, Cruz-Sanchez FF (2000) Apolipoprotein E genotype in Spanish schizophrenic patients. Psychiatr Genet 10:73-77

Fisman M, Rabheru K, Hegele RA, Sharma V, Fisman D, Doering M, Appell J (2001) Apolipoprotein E polymorphism and response to electroconvulsive therapy. J ECT 17:11-14

Gerdes LU (2003) The common polymorphism of apolipoprotein E: geographical aspects and new pathophysiological relations. Clin Chem Lab Med 41:628-631

Harrington CR, Roth M, Xuereb JH, McKenna PJ, Wischik CM (1995) Apolipoprotein E type epsilon 4 allele frequency is increased in patients with schizophrenia. Neurosci Lett 202:101104

Hata T, Kunugi H, Nanko S, Fukuda R, Kaminaga T (2002) Possible effect of the APOE epsilon 4 allele on the hippocampal volume and asymmetry in schizophrenia. Am $\mathbf{J}$ Med Genet 114:641-642

Hong CJ, Yu YW, Lin CH, Song HL, Lai HC, Yang KH, Tsai SJ (2000) Association study of apolipoprotein E epsilon4 with clinical phenotype and clozapine response in schizophrenia. Neuropsychobiology 42:172-174

Igata-Yi R, Igata T, Ishizuka K, Kimura T, Sakamoto S, Katsuragi S, Takamatsu J, Miyakawa T (1997) Apolipoprotein E genotype and psychosis. Biol Psychiatry 41:906-908

Jonsson E, Lannfelt L, Engvall B, Sedvall G (1996) Lack of association between schizophrenia and the apolipoprotein E epsilon 4 allele. Eur Arch Psychiatry Clin Neurosci 246:182-184
Kimura T, Yokota S, Igata-Yi R, Shono M, Takamatsu J, Miyakawa T (1997) Apolipoprotein E epsilon2 allele and early onset schizophrenia. Neurosci Lett 231:53-55

Koch W, Ehrenhaft A, Griesser K, Pfeufer A, Muller J, Schomig A, Kastrati A (2002) TaqMan systems for genotyping of disease-related polymorphisms present in the gene encoding apolipoprotein E. Clin Chem Lab Med 40:1123-1131

Liu W, Breen G, Zhang J, Li S, Gu N, Feng G, Bai S, Shen T, Yu A, Xue H, St Clair D, He L (2003) Association of APOE gene with schizophrenia in Chinese: a possible risk factor in times of malnutrition. Schizophr Res 62:225-230

Livak KJ (1999) Allelic discrimination using fluorogenic probes and the $5^{\prime}$ nuclease assay. Genet Anal 14:143-149

Mahley RW, Rall SC Jr (2000) Apolipoprotein E: far more than a lipid transport protein. Annu Rev Genomics Hum Genet 1:507537

Martorell L, Virgos C, Valero J, Coll G, Figuera L, Joven J, Pocovi M, Labad A, Vilella E (2001) Schizophrenic women with the APOE epsilon 4 allele have a worse prognosis than those without it. Mol Psychiatry 6:307-310

Murphy GM, Kremer C, Rodrigues H, Schatzberg AF, Mitrazapine versus paroxetine Study, Group (2003) The apolipoprotein E epsilon4 allele and antidepressant efficacy in cognitively intact elderly depressed patients. Biol Psychiatry 54:665-673

Nathan BP, Jiang Y, Wong GK, Shen F, Brewer GJ, Struble RG (2002) Apolipoprotein E4 inhibits, and apolipoprotein E3 promotes neurite outgrowth in cultured adult mouse cortical neurons through the low-density lipoprotein receptor-related protein. Brain Res 928:96-105

Pickar D, Malhotra AK, Rooney W, Breier A, Goldman D (1997) Apolipoprotein E epsilon 4 and clinical phenotype in schizophrenia. Lancet 350:930-931

Saiz PA, Morales B, G-Portilla MP, Alvarez V, Coto E, Fernandez JM, Bousono M, Bobes J (2002) Apolipoprotein E genotype and schizophrenia: further negative evidence. Acta Psychiatr Scand 105:71-75

Schurhoff F, Krebs MO, SzA ke A, Loze JY, Goldberger C, Quignon V, Tignol J, Rouillon F, Laplanche JL, Leboyer M (2003) Apolipoprotein E in schizophrenia: a French association study and meta-analysis. Am J Med Genet 119B:18-23

Siest G, Pillot T, Regis-Bailly A, Leininger-Muller B, Steinmetz J, Galteau MM, Visvikis S (1995) Apolipoprotein E: an important gene and protein to follow in laboratory medicine. Clin Chem 41:1068-1086

Siest G, Bertrand P, Herbeth B, Vincent-Viry M, Schiele F, Sass C, Visvikis S (2000) Apolipoprotein E polymorphisms and concentration in chronic diseases and drug responses. Clin Chem Lab Med 38:841-852

Sutcliffe JG, Thomas EA (2002) The neurobiology of apolipoproteins in psychiatric disorders. Mol Neurobiol 26:369-388

Thomas EA, Laws SM, Sutcliffe JG, Harper C, Dean B, McClean C, Masters C, Lautenschlager N, Gandy SE, Martins RN (2003) Apolipoprotein D levels are elevated in prefrontal cortex of subjects with Alzheimer's disease: no relation to apolipoprotein E expression or genotype. Biol Psychiatry 54:136-141

Weisgraber KH, Rall SC Jr, Mahley RW (1981) Human E apoprotein heterogeneity. Cysteine-arginine interchanges in the amino acid sequence of the apo-E isoforms. J Biol Chem 256:9077-9083 